\title{
Load Sharing of Wind Based Microgrid in Autonomous Operation
}

\author{
Aarti Gupta, Dinesh Kumar Jain, and Surender Dahiya \\ DCRUST, Murthal 131001, India \\ Correspondence should be addressed to Aarti Gupta; aartigupta45@gmail.com \\ Received 1 September 2014; Accepted 10 December 2014; Published 30 December 2014 \\ Academic Editor: Malabika Basu
}

Copyright (C) 2014 Aarti Gupta et al. This is an open access article distributed under the Creative Commons Attribution License, which permits unrestricted use, distribution, and reproduction in any medium, provided the original work is properly cited.

\begin{abstract}
Autonomous wind energy conversion systems sharing a common load consist of a number of voltage source converters operating in parallel. A suitable control system should ensure desired load sharing among these as a number of these sources operating in parallel are required to meet the load demand and load excursions should not lead to instability of the system. In absence of the grid there is no reference angle for synchronization. Hence, a control scheme for parallel-connected three-phase converters incorporating the desirable features needs to be developed in order to exploit the renewable energy sources, which are intermittent in nature as effectively as possible in case of an autonomous microgrid. A simple and effective droop control strategy without the use of conventional $\alpha \beta$ technique incorporating only $d q$ components has been proposed for load sharing among wind energy conversion systems connected by back to back voltage source converters in autonomous operation. The need for communication link should also be avoided, hence reducing the system cost. The system is modelled using Matlab and the control is authenticated by simulation results.
\end{abstract}

\section{Introduction}

Due to increased penetration of renewable energy sources, particularly wind, the number of DG (distributed generator) units operating autonomously is on the rise. Islanded microgrids can find application in remote places where main grid is unavailable. In this configuration, the microgrid elements are responsible for voltage and power control. The microgrid consisting of supply, load, and storage is a fully controlled entity. A single autonomous unit is of low power capacity; hence operation of a cluster of DGs is responsible for feeding the load. Maintaining the balance of power in autonomous mode requires the participation of all DGs, and this has attracted the attention of several researchers. The DGs in a microgrid, which is operated in islanding mode, should share power between each other in an appropriate ratio to prevent circulating current and thermally overstressing or damaging of components [1].

In the conventional electrical network with synchronous generator, any alteration in active power balance causes change in synchronous frequency. Load frequency control is achieved by the active power regulation of the synchronous generators. In absence of a synchronous generator, this conventional method cannot work. In this situation, in absence of a regular grid, there are two methods to control voltage source converter- (VSC-) based microgrids. A well-planned coordinated control is required to utilize these resources efficiently. The first control technique employs communication links such as the master-slave approach which are used for microsources operating within a particular area. In the second case, power sharing is achieved by the real powerfrequency droop $(P-\omega)$ control and the reactive powervoltage droop $(Q-V)$ droop control in the droop-controlled renewable power system [1-3]. The elimination of communication link makes the generation truly distributive in nature and considerably reduces the cost of the system. The $P-\omega$ droop control can achieve accurate real power sharing results while the $Q-V$ droop control helps to achieve better proportional sharing of reactive power [4-6]. Droop controllers are adopted in autonomously operated systems. The droop control uses the real power out of a generator to calculate the ideal operating frequency. This relaxing of a stiff frequency allows the microgrid to dampen the fast effects of changing loads, increasing the stability of the system. Droop power systems 


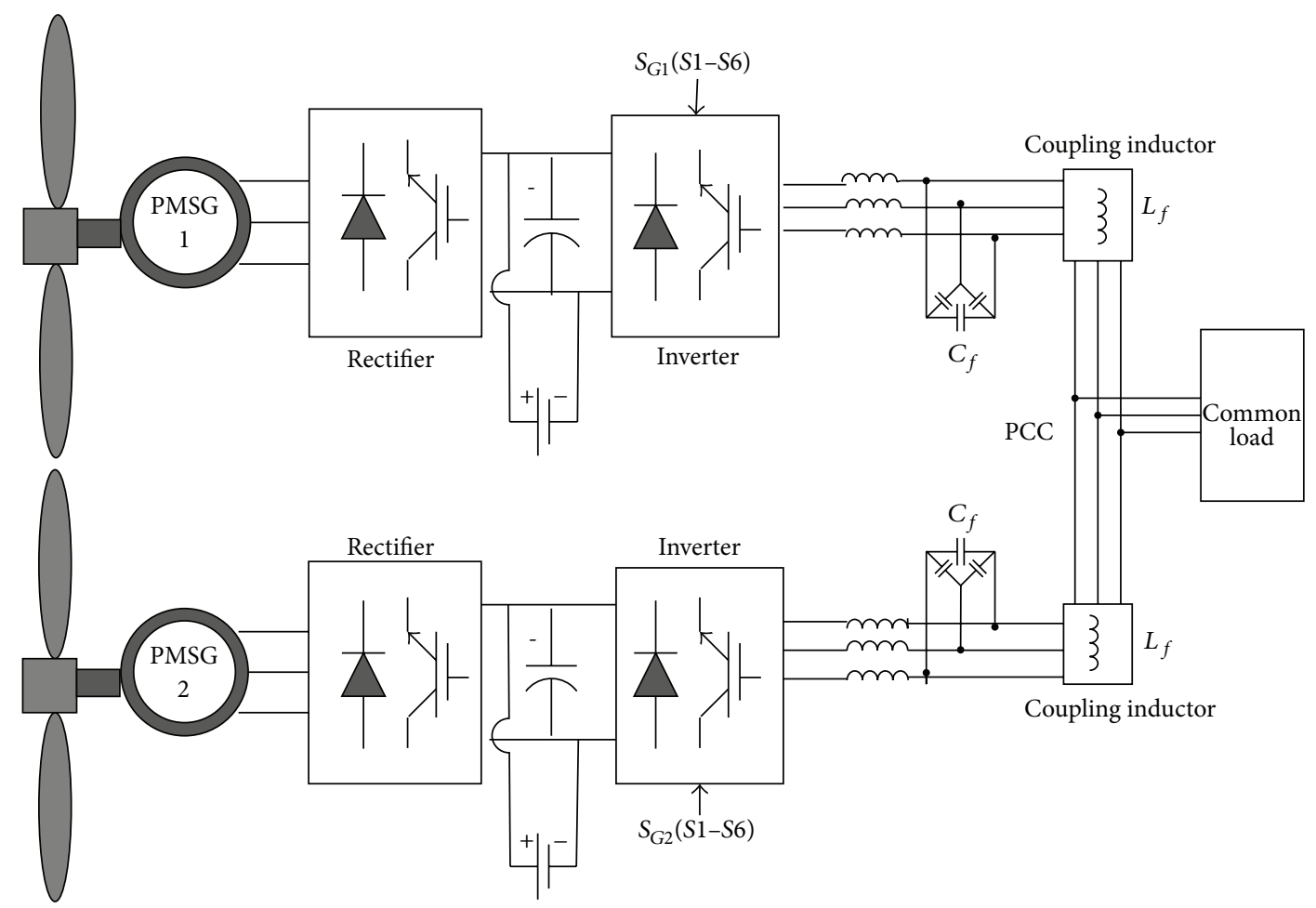

FIGURE 1: Schematic of back to back three-phase parallel converter in autonomous operation.

can be connected to highly intermittent supply like wind based energy sources [7-10]. The avoidance of communication link makes it a reliable and highly competitive option.

This paper proposes coordinated load sharing among two PMSG (permanent magnet synchronous generator) based wind driven distributed generators sharing a common load in autonomous operation without using the traditional $\alpha \beta$ transformation. Only $d q$ components are used for control. Hence, the control scheme is simple yet effective. In most droop control systems the source is dynamically modelled or the DC voltage is assumed to be fixed [11]. The system uses two PMSG based WECS for analysis of results. Moreover, load perturbations lead to a change in DC link voltage affecting the PCC (point of common coupling) voltage. Fastresponse energy storage module (BESS) has been included in each WECS to provide a constant DC voltage. This method can also be further applied to many VSC connected generators feeding a common load. This paper is organized as follows. In Section 2, the microgrid components are explained briefly. The control designs of the droop based power controller and voltage and current control controller are presented in Section 3. Section 4 presents the simulation results and related discussion of the paralleled two $15 \mathrm{~kW}$ inverter system. Finally, Section 5 concludes this paper.

\section{Microgrid Components}

The major components of each VSC-based microgrid are the VSCs, generators, output filter and coupling inductance, DC bus, and battery and load. The schematic of the proposed system is shown in Figure 1. The DG in this case is $15 \mathrm{~kW}$ PMSG based WECS (wind energy conversion system). The output voltage of each inverter is related to DC voltage by modulation index (MI).

The inverter controllers MI have a maximum allowable value based on inverter structure and switching strategy. If $I_{d 1^{*}}$ and $I_{q 1^{*}}$ are the reference $d$ and $q$ axis currents generated by the autonomous inverter and $V_{\mathrm{dc}}$ is the DC link voltage, then

$$
\mathrm{MI}_{\mathrm{MAX}}=\frac{\sqrt{I_{d 1^{* 2}}+I_{q 1^{* 2}}}}{V_{\mathrm{dc}} / 2} .
$$

However, if DC voltage reduces drastically so that the MI becomes greater than the inverter $\mathrm{MI}_{\mathrm{MAX}}$, it cannot supply the reference voltage. Reference [6] demonstrates the fact that when the DC voltage is fixed, the switching process can be neglected and the inverter produces the reference voltage. In this condition, the dynamics of primary source has no effect on VSC output voltage. Hence, a fast-response BESS (battery energy storage system) is integrated at the DC link of each VSC-based DG with the help of a buck-boost converter to overcome the voltage fluctuations due to the intermittent wind conditions.

\section{Autonomous Inverter Controller}

This model consists of power sharing controller, the voltage controller, and current controller. Figure 2 shows the control of the autonomous inverter controller. The voltage and current controller can track the voltage references produced by 

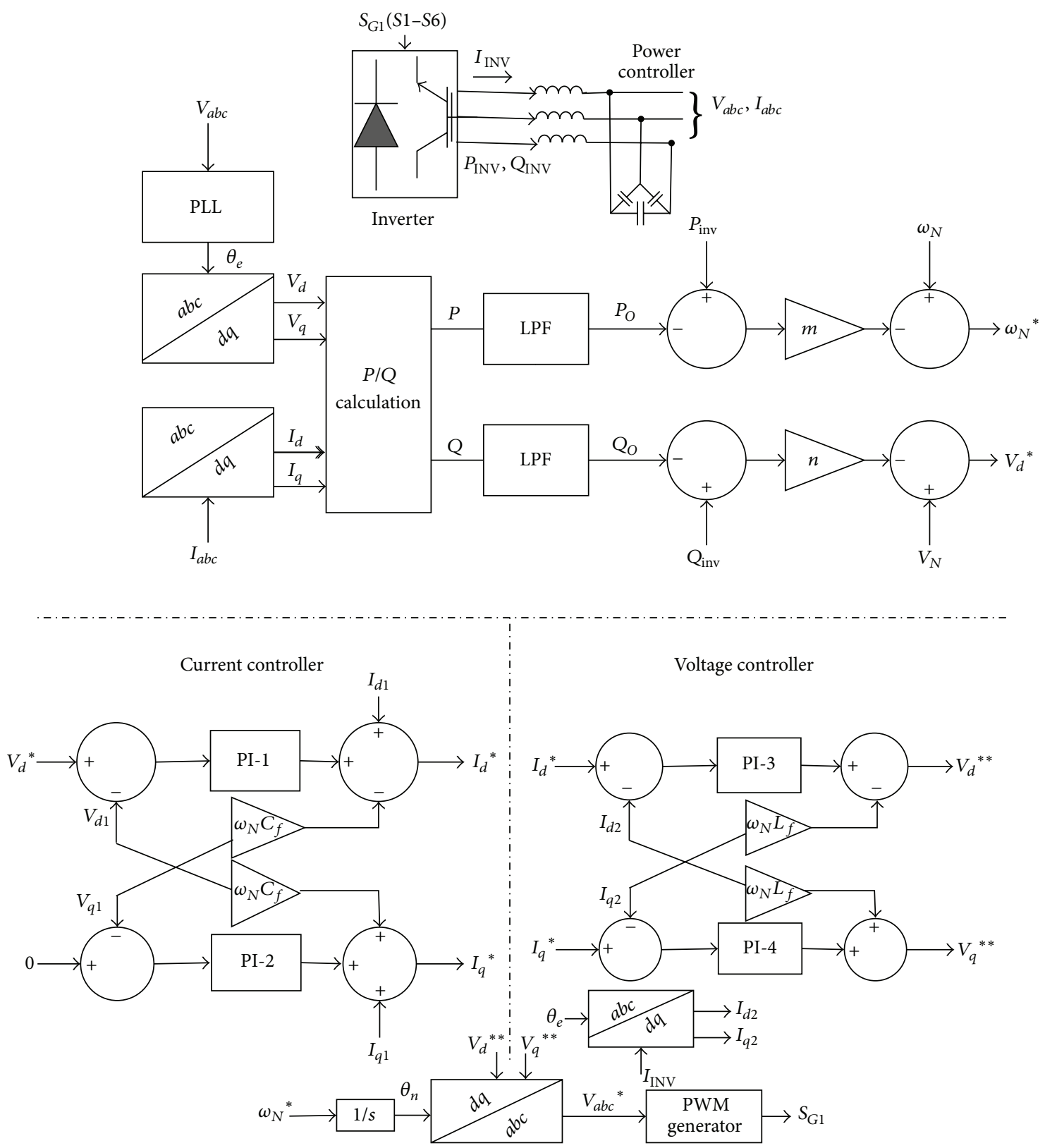

FIGURE 2: Autonomous inverter controller.

the droop controller. Adjustment of droop coefficients is necessary as effective power sharing cannot be achieved, at the expense of degrading the voltage regulation [12]. The control scheme of the one of the autonomous generator is detailed in the present section.

3.1. Power Sharing Controller. The power sharing controller of microgrids is based on microgrid frequency and voltage droop method. Assuming that the active power is related to the phase angles differences, while the reactive power depends on the voltage magnitudes, the active and reactive power can be controlled by adjusting the DG output frequency and magnitude of voltage, respectively. $\theta_{e}$ is the reference angle obtained from PLL (phase locked loop) where $V_{d}$,
$V_{q}$ and $I_{d}, I_{q}$ are the direct and quadratic component voltage of $V_{a b c}$ and inverter output current, $I_{a b c}$, respectively, at the output of the filter capacitor. The active power and reactive power are calculated by using the following common equations:

$$
\begin{gathered}
P=V_{d} I_{d}+V_{q} I_{q}, \\
Q=V_{q} I_{d}-V_{d} I_{q} .
\end{gathered}
$$

After passing through low pass filters with cut-off frequency equal to $\omega_{c}$, the outputs $P_{O}$ and $Q_{O}$ are compared to $P_{\text {inv }}$ and $Q_{\text {inv }}$, the average output active and reactive power, 
respectively, of the WECS. $\omega_{N}^{*}$ is calculated where $m$ represents the $P-\omega$ droop coefficient and $\omega_{N}$ is the nominal frequency:

$$
\omega_{N}^{*}=\omega_{N}-m\left(P_{\mathrm{O}}-P_{\mathrm{INV}}\right) .
$$

According to the frequency droop schemes the droop coefficients $\left(m_{1}\right.$ and $\left.m_{2}\right)$ are taken as inversely proportional to the DG rating $\left(p_{1}\right.$ and $\left.p_{2}\right)$. Hence this method allows load sharing without the communication channel. " $n$ " is the gain of the $Q$ $V$ droop. The direct axis reference voltage is thus obtained where $V_{n}$ is the nominal voltage. Hence,

$$
\begin{gathered}
\frac{m_{1}}{m_{2}}=\frac{p_{1}}{p_{2}}, \\
V_{d}^{*}=V_{n}-n\left(Q_{O}-Q_{\mathrm{INV}}\right), \\
V_{q}^{*}=0 .
\end{gathered}
$$

3.2. Voltage Controller. The control algorithm for the controller is as follows. $V_{d}^{*}$ is the reference obtained from the power controller direct axis reference current $\left(I_{d}^{*}\right)$ which is obtained as follows:

$$
I_{d}^{*}=-\omega_{N} C_{f} V_{q}+K_{p 1}\left(V_{d}^{*}-V_{d}\right)+K_{i 1} \int\left(V_{d}^{*}-V_{d}\right),
$$

where $K_{p 1}$ and $K_{i 1}$ are the proportional integral controller (PI-1) gains and $C_{f}$ is the filter capacitance. Similarly $I_{q}^{*}$ the quadrature axis reference current is given by (8), where $K_{p 2}$ and $K_{i 2}$ represent the gain of the second controller (PI-2):

$$
I_{q}^{*}=\omega_{N} C_{f} V_{d}+K_{p 2}\left(V_{q}^{*}-V_{q}\right)+K_{i 2} \int\left(V_{q}^{*}-V_{q}\right)
$$

3.3. Current Controller. In the inner current loop, $I_{d 2}$ and $I_{q 2}$ are obtained by the $a b c$ to $d q$ transformation of $I_{\text {inv }}$ (inverter current).

The quadrature axis reference voltage is set to zero; in (6) the difference between the obtained reference current of the current controller $I_{d 1}^{*}$ and $I_{q 1}^{*}$ is compared to $I_{d 2}$ and $I_{q 2}$ obtained by the $a b c$ to $d q$ transformation of $I_{\text {inv }}$ (inverter current).

The reference $V_{d}^{* *}$ is obtained as per the following equation:

$$
V_{d}^{* *}=-\omega_{N} L_{f} I_{q 2}^{*}+K_{p 3}\left(I_{d}^{*}-I_{d 2}\right)+K_{i 3} \int\left(I_{d}^{*}-I_{d 2}\right) .
$$

$K_{p 3}$ and $K_{i 3}$ are gains, respectively, of the proportional integral controller (PI-3). Similarly, reference $V_{q}^{* *}$ is derived from controller (PI-4):

$$
V_{q}^{* *}=\omega_{N} L_{f} I_{d 2}^{*}+K_{p 4}\left(I_{q}^{*}-I_{q 2}\right)+K_{i 4} \int\left(I_{q}^{*}-I_{q 2}\right),
$$

with gains $K_{p 3}$ and $K_{i 3}$, respectively. $L_{f}$ represents the filter inductance. The $V_{d}^{* *}$ and $V_{q}^{* *}$ are converted into $V_{a b c}^{*}$ by $d q$ to $a b c$ transformation with reference $\omega_{N}^{*}$ obtained by the power controllers:

$$
\theta_{N}=\int \omega_{N}^{*}
$$

$V_{a b c}^{*}$ is given to PWM generator which generates the control signal, $S_{\mathrm{GI}}$, of the PWM inverter. The reference signal $S_{\mathrm{G} 2}$ of the second autonomous inverter is similarly generated.

\section{Simulation Study}

Figures 3, 4, 5, and 6 show the simulation results with the proposed control scheme using the Matlab/Simulink software. In Figure 3, the simulation results of equal active power sharing of the two WECS between the intervals of $1 \mathrm{sec}$ to 3 seconds are shown. The DC voltages are almost fixed during simulation and the MI remains in allowable range since the battery storage system has rapid dynamics. The constraints of voltage and frequency have to be adhered along with power sharing; hence an appropriate value of coefficients $m$ and $n$ is chosen. A total load of $18 \mathrm{~kW}\left(P_{L}\right)$ is shared equally by both wind generators. The voltage magnitude at the PCC $\left(V_{\mathrm{PCC}}\right)$ is balanced. The current waveform of VSCs $\left(I_{\mathrm{INV} 1}\right.$ and $\left.I_{\mathrm{INV} 2}\right)$ is shown along with load current $\left(I_{l}\right)$ between the intervals $1 \mathrm{sec}$ to $1.5 \mathrm{sec}$ for active equal power sharing. The load current of $38 \mathrm{~A}$ is shared almost equally by the two DGs. The frequency at PCC $\left(W_{\text {PCC }}\right)$ and the frequency of the two DGs $\left(W_{1}\right.$ and $W_{2}$ ) are also shown.

Figure 4 shows the result for equal active and reactive load sharing. The results for reactive power sharing validate the fact that the load of $10 \mathrm{KVAR}\left(Q_{L}\right)$ is shared equally by both the WECS $\left(Q_{1}\right.$ and $Q_{2}$, resp.) as is the active power $\left(P_{1}\right.$ and $\left.P_{2}\right)$.

In Figure 5, the frequency droop gain for first generator is set to $m_{1}$ and the droop gain of the second generator is set to $m_{2}$. The frequency droop gain of one WECS is set more than the other. The load of $12 \mathrm{~kW}$ is shared of which $5 \mathrm{~kW}$ is supplied by first wind generator whereas $7 \mathrm{~kW}$ is supplied by second wind generator. The voltage waveforms and frequency at PCC are also shown for $m_{1} \neq m_{2}$ between the intervals of $1 \mathrm{sec}$ to $3 \mathrm{sec}$. Load is shared as per requirement by varying the droop gain.

The system is studied for varying wind and load conditions in Figure 6. Initially a common load of $6 \mathrm{~kW}$ was shared by both the generators with equal frequency droop coefficient, hence effecting equal load sharing as explained in Section 2. The load demand increment is shared between both the AC sources perfectly as validated by simulation results for a period of $3.5 \mathrm{sec}$. At $t=1 \mathrm{sec}$, the load is increased by $6 \mathrm{~kW}$ by switching on the $\mathrm{CB}$ (circuit breaker), generation output of first AC generator $\left(P_{1}\right)$ and output of second AC generator $\left(P_{2}\right)$ increase to compensate the increased load demand, and system frequency at the point of common coupling $\left(w_{\mathrm{pcc}}\right)$ remains constant at the desired frequency of $50 \mathrm{~Hz}$. At $t=2 \mathrm{sec}$, the load is increased by $4 \mathrm{~kW}$ which is compensated by both the generators.

At $t=3 \mathrm{sec}$, the additional loads of $6 \mathrm{~kW}$ and $4 \mathrm{~kW}$ are removed by switching off the CBs and the generation is curtailed for both the AC sources accordingly. $V_{\mathrm{DC} 1}$ and $V_{\mathrm{DC}}$ 

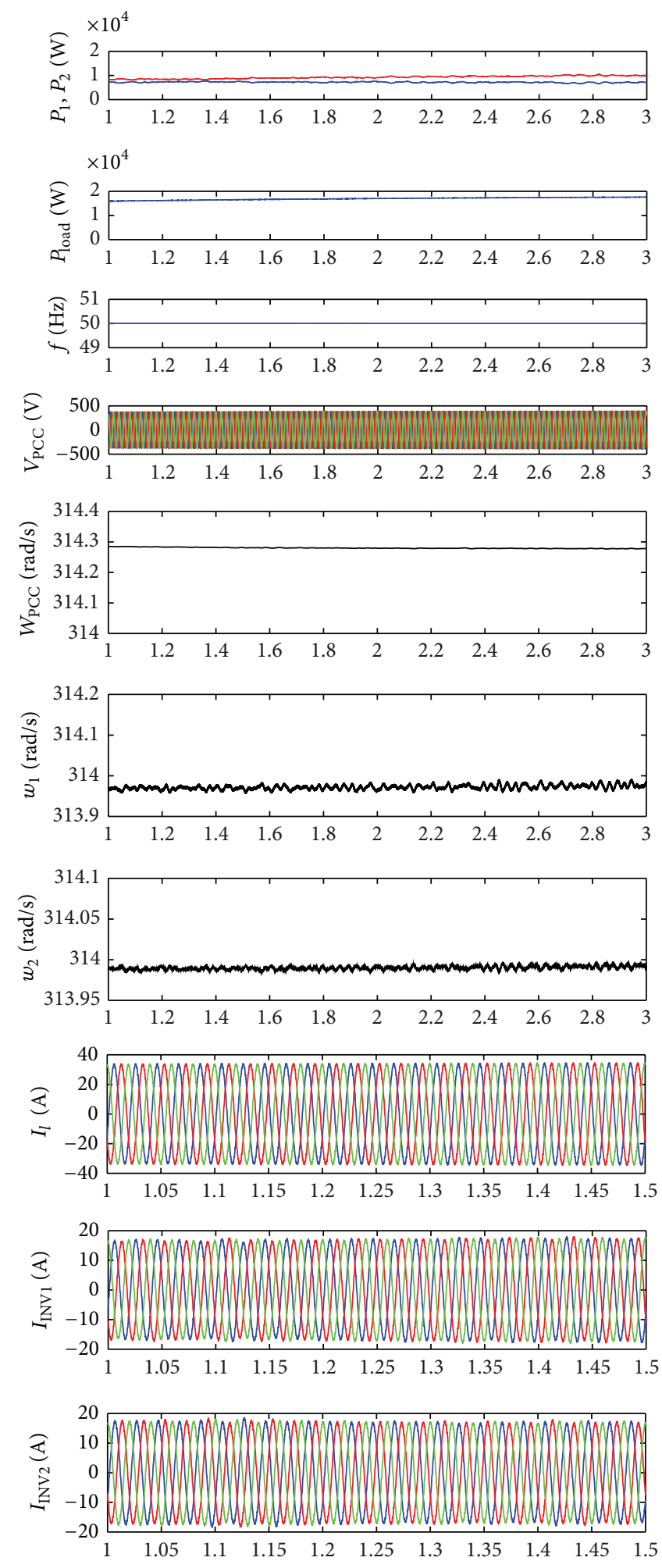

FIgURE 3: Equal load sharing $\left(m_{1}=m_{2}\right)$.

represent the DC link voltage of the two parallel converters of the AC subgrid. The respective wind speed inputs of the wind turbines are shown as $w s_{1}$ and $w s_{2}$ in the figure. The wind speed input is varied from $10 \mathrm{~m} / \mathrm{s}$ to $15 \mathrm{~m} / \mathrm{s}$ in steps for both wind turbine generators but the intermittent wind conditions do not affect the system performance under varying wind condition due to BESS interfaced at the DC link. Hence, the implemented droop-controlled system is stable for a cluster of distributed $\mathrm{AC}$ resources sharing a common load using parallel back to back converters. 

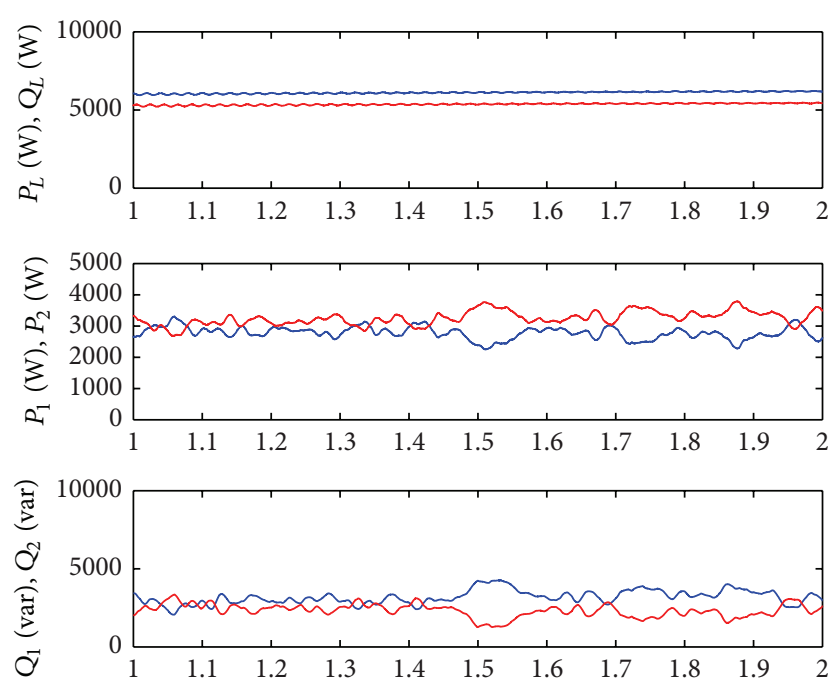

FIGURE 4: Unequal active and reactive power sharing.
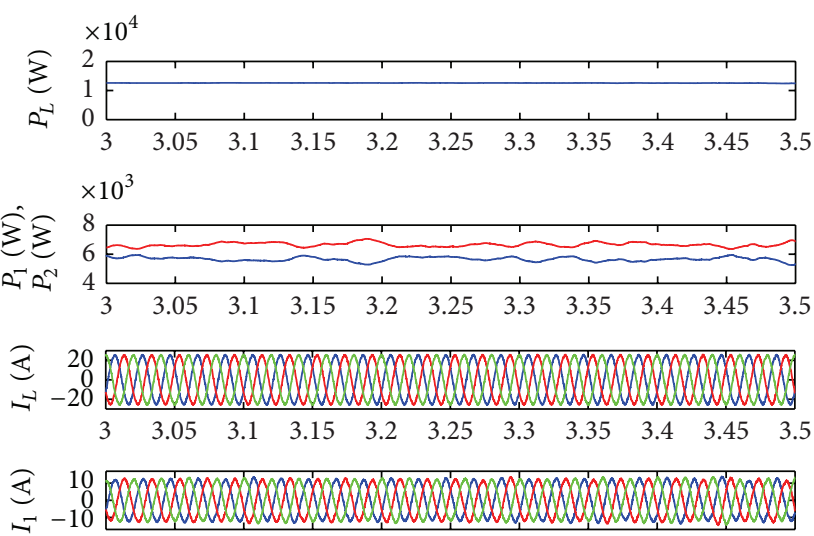

$\begin{array}{lllllllllll}3 & 3.05 & 3.1 & 3.15 & 3.2 & 3.25 & 3.3 & 3.35 & 3.4 & 3.45 & 3.5\end{array}$

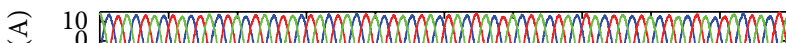

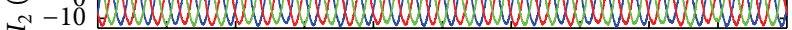

$\begin{array}{lllllllllll}3 & 3.05 & 3.1 & 3.15 & 3.2 & 3.25 & 3.3 & 3.35 & 3.4 & 3.45 & 3.5\end{array}$

FIGURE 5: Unequal active power sharing $\left(m_{1} \neq m_{2}\right)$.

\section{Conclusion}

With increased penetration of the renewable energy sources power curtailing has to be resorted in order to ensure requisite load sharing between microsources. A simple and viable control strategy without the conventional $\alpha \beta$ technique has been validated for load sharing among WECS connected by back to back VSCs in autonomous operation. The proposed system shows a good voltage regulation and a stable response when subjected to load transients as well as wind speed variations which is validated by Matlab simulations.

\section{Appendix}

See Table 1.
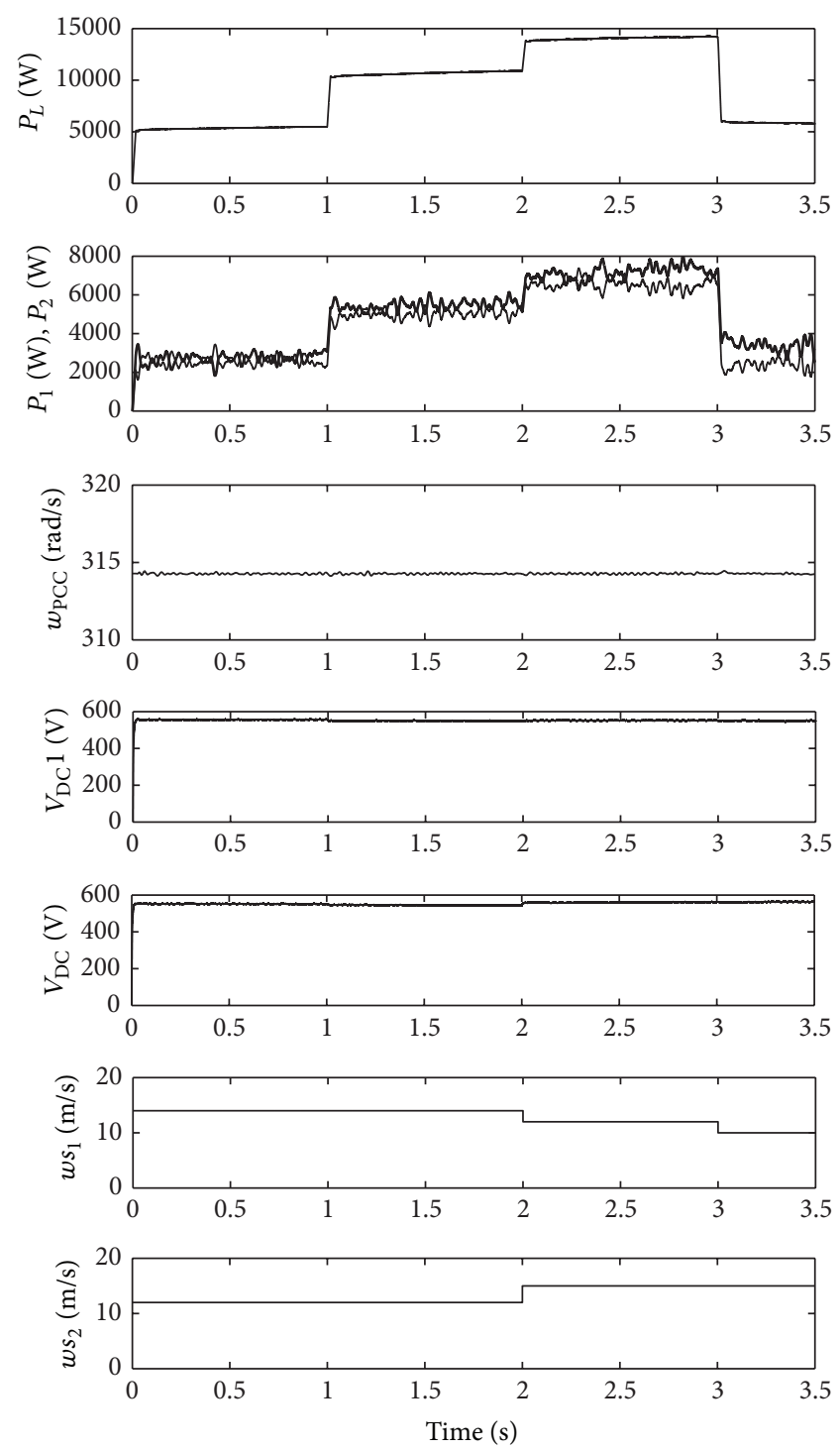

Figure 6: Response to varying wind and load.

TABLE 1: Parallel inverter parameters.

\begin{tabular}{lcc}
\hline Parameters & Inverter 1 & Inverter 2 \\
\hline Frequency droop coefficient, $m$ & $3 \times 10^{-5}$ & $3 \times 10^{-5}$ \\
Amplitude droop coefficient, $n$ & $8 \times 10^{-3}$ & $8 \times 10^{-3}$ \\
DC link voltage & $500 \mathrm{~V}$ & $500 \mathrm{~V}$ \\
Filter inductance & $2 \mathrm{mH}$ & $2 \mathrm{mH}$ \\
Filter capacitance & $11 \mu \mathrm{F}$ & $11 \mu \mathrm{F}$ \\
\hline
\end{tabular}

\section{Conflict of Interests}

The authors declare that there is no conflict of interests regarding the publication of this paper.

\section{References}

[1] P. H. Divshali, A. Alimardani, S. H. Hosseinian, and M. Abedi, "Decentralized cooperative control strategy of microsources for 
stabilizing autonomous VSC-based microgrids," IEEE Transactions on Power Systems, vol. 27, no. 4, pp. 1949-1959, 2012.

[2] F. Katiraei, R. Iravani, N. Hatziargyriou, and A. Dimeas, "Microgrids management," IEEE Power and Energy Magazine, vol. 6, no. 3, pp. 54-65, 2008.

[3] C.-L. Chen, Y. Wang, J.-S. Lai, Y.-S. Lee, and D. Martin, “Design of parallel inverters for smooth mode transfer microgrid applications," IEEE Transactions on Power Electronics, vol. 25, no. 1, pp. 6-15, 2010.

[4] J. Rocabert, G. M. S. Azevedo, A. Luna, J. M. Guerrero, J. I. Candela, and P. Rodrguez, "Intelligent connection agent for three-phase grid-connected microgrids," IEEE Transactions on Power Electronics, vol. 26, no. 10, pp. 2993-3005, 2011.

[5] J. M. Guerrero, L. G. de Vicuña, J. Matas, M. Castilla, and J. Miret, "Output impedance design of parallel-connected UPS inverters with wireless load-sharing control," IEEE Transactions on Industrial Electronics, vol. 52, no. 4, pp. 1126-1135, 2005.

[6] C. K. Sao and P. W. Lehn, "Autonomous load sharing of voltage source converters," IEEE Transactions on Power Delivery, vol. 20, no. 2, pp. 1009-1016, 2005.

[7] J. Kim, J. M. Guerrero, P. Rodriguez, R. Teodorescu, and K. Nam, "Mode adaptive droop control with virtual output impedances for an inverter-based flexible AC microgrid," IEEE Transactions on Power Electronics, vol. 26, no. 3, pp. 689-701, 2011.

[8] Y. A.-R. I. Mohamed and A. A. Radwan, "Hierarchical control system for robust microgrid operation and seamless mode transfer in active distribution systems," IEEE Transactions on Smart Grid, vol. 2, no. 2, pp. 352-362, 2011.

[9] J. Kim, J. M. Guerrero, P. Rodriguez, R. Teodorescu, and K. Nam, "Mode adaptive droop control with virtual output impedances for an inverter-based flexible AC microgrid," IEEE Transactions on Power Electronics, vol. 26, no. 3, pp. 689-701, 2011.

[10] C.-T. Lee, C.-C. Chu, and P.-T. Cheng, "A new droop control method for the autonomous operation of distributed energy resource interface converters," in Proceedings of the 2nd IEEE Energy Conversion Congress and Exposition (ECCE '10), pp. 702709, Atlanta, Georgia, USA, September 2010.

[11] N. Pogaku, M. Prodanović, and T. C. Green, "Modeling, analysis and testing of autonomous operation of an inverter-based microgrid," IEEE Transactions on Power Electronics, vol. 22, no. 2, pp. 613-625, 2007.

[12] J. C. Vasquez, J. M. Guerrero, M. Savaghebi, J. Eloy-Garcia, and R. Teodorescu, "Modeling, analysis, and design of stationaryreference-frame droop-controlled parallel three-phase voltage source inverters," IEEE Transactions on Industrial Electronics, vol. 60, no. 4, pp. 1271-1280, 2013. 


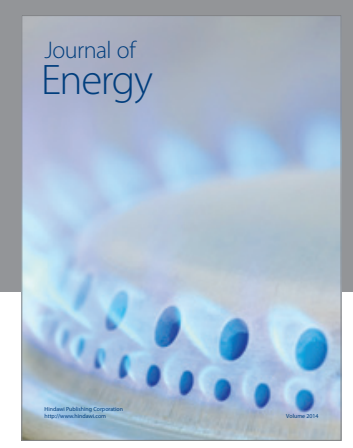

Journal of

Industrial Engineering
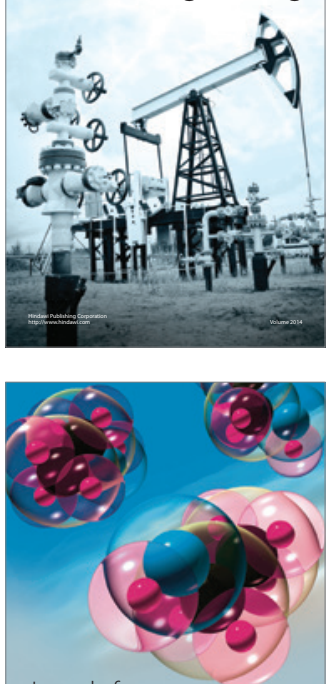

Fuels
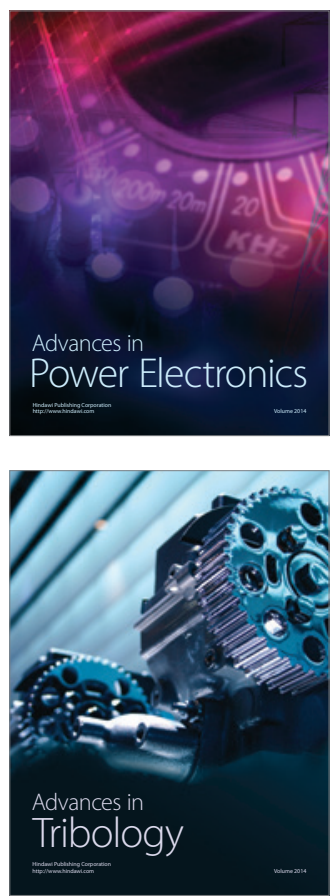

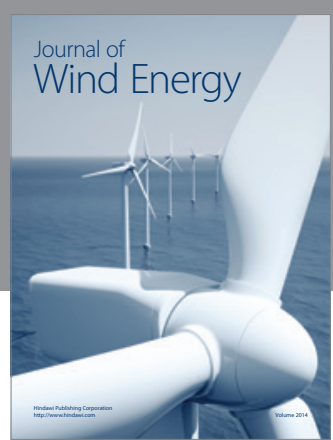

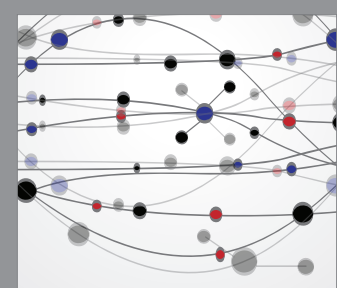

The Scientific World Journal

Submit your manuscripts at http://www.hindawi.com

Journal of

Structures
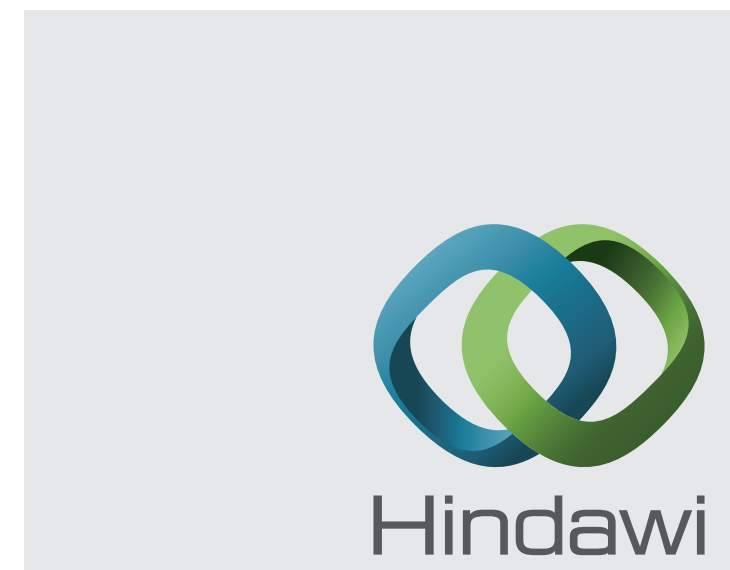

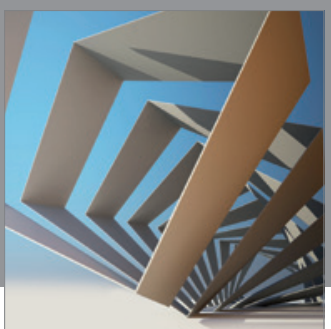

Rotating

Machinery
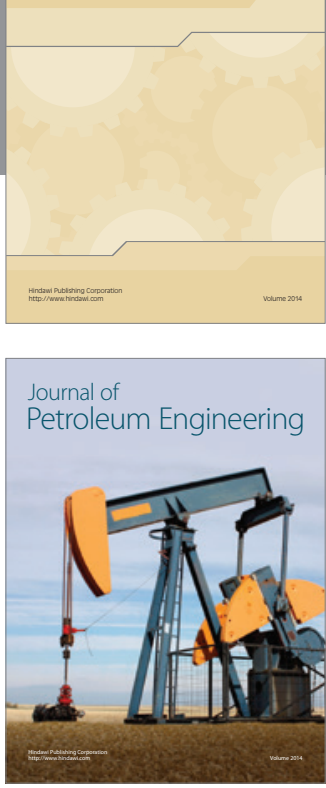

Journal of

Solar Energy
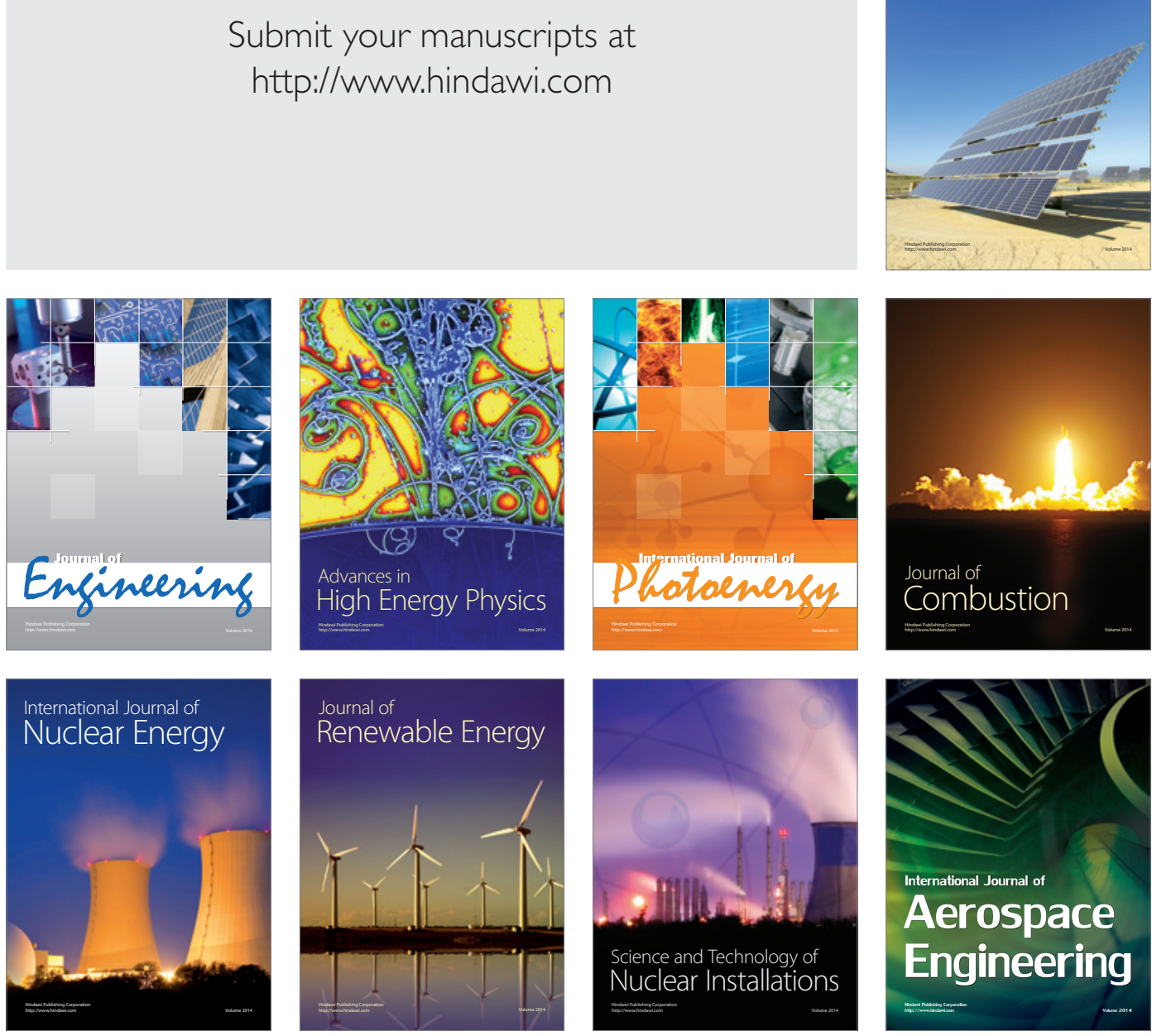